\title{
Successful Removal of Intracavernous Neurinoma Originating from the Oculomotor Nerve
}

\author{
-Case Report-
}

\author{
Yasutaka Kurokawa, Teiji Uede, Osamu Honda and Osamu HonMOU
}

Department of Neurosurgery, Kushiro City General Hospital, Kushiro, Hokkaido

\begin{abstract}
An oculomotor neurinoma was confirmed intraoperatively to be located in the lateral wall of the cavernous sinus in a 55-year-old male. By protruding into the true venous cavity, it caused obliteration of the blood flow in the cavernous sinus. The tumor was totally removed without entering the true venous cavity of the cavernous sinus. The cavernous sinus was closed by suturing the dural membrane to the thin fibrous membrane, preventing intraoperative bleeding.
\end{abstract}

Key words: cavernous sinus, neurinoma, operative procedure, oculomotor nerve

\section{Introduction}

Neurinomas originating on motor nerves are extremely rare. Successful removal of oculomotor neurinoma with intraoperative confirmation of origin is unusual. The cavernous sinus is considered a difficult surgical area, but benign tumors such as neurinoma in the lateral wall of the sinus can be removed safely. We report the successful removal of a neurinoma arising from the oculomotor nerve in the cavernous sinus.

\section{Case Report}

A 55-year-old male was healthy until he experienced double vision. Two weeks later, he suddenly noticed right blephaloptosis. Right oculomotor nerve paresis was diagnosed at a local hospital. He was admitted to our institute a fortnight later on October 18, 1990.

Physical examination revealed no sign of von Recklinghausen's disease. Neurological examination found right oculomotor nerve paralysis, right abducens nerve paresis, and slight hypesthesia on the right face. Optic fundi were normal. Computed tomographic scans suggested an enlarged right cavernous sinus. Magnetic resonance (MR) images

Received April 12, 1991; Accepted September 20, 1991 clearly revealed a round tumor on the lateral wall of the right cavernous sinus (Fig. 1). Only the tumor periphery was enhanced suggesting an intratumoral cyst. Right carotid angiograms showed medial displacement of the intracavernous portion of the internal carotid artery, without associated aneurysm or tumor stain. However, the right cavernous sinus was not filled even in the late venous phase. The neurological deficit continued despite $160 \mathrm{mg}$ methylprednisolone daily for 7 days.

The tumor was removed through the right fron-

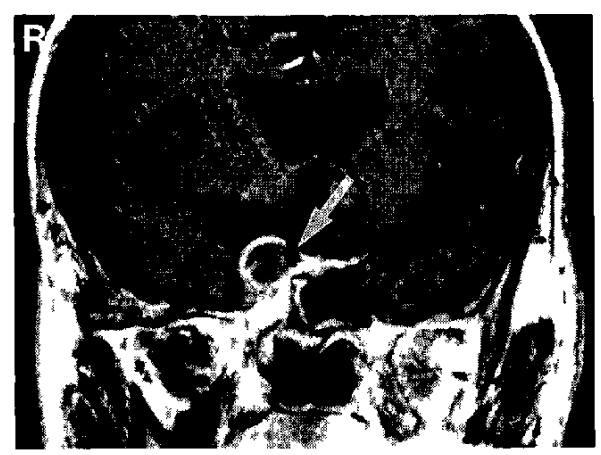

Fig, 1 Postcontrast $T_{1}$-weighted MR image, showing a well-demarcated tumor mainly situated in the lateral wall of the right cavernous sinus (arrowheads). Internal carotid artery displaced medially (arrow) by the tumor. 
totemporal pterional approach on November 5, 1990. The superolateral wall of the right cavernous sinus markedly protruded (Fig. 2A) and the oculomotor nerve was apparently swollen at the entrance to the cavernous sinus (Fig. 2B). The anterior clinoid process was drilled away, exposing the anterior triangle of Dolenc') (Fig. 2C). The outer dura of the superolateral wall of the cavernous sinus was incised along the course of the oculomotor nerve. Following these procedures, part of the yellowish tumor appeared through the thin fibrous membrane. The thin membrane was opened along the dural incision. When the intratumoral cyst was evacuated, marked pulsatile bleeding, synchronized with the respiration, originated between the outer dural wall and the inner fibrous membrane. However, complete hemostasis was easily obtained by microsurgical suturing of this outer dural wall with the inner thin membrane. The tumor could then be decompressed by evacuation of the intratumoral cyst fluid. It was then clearly recognized that the tumor originated from the oculomotor nerve in the

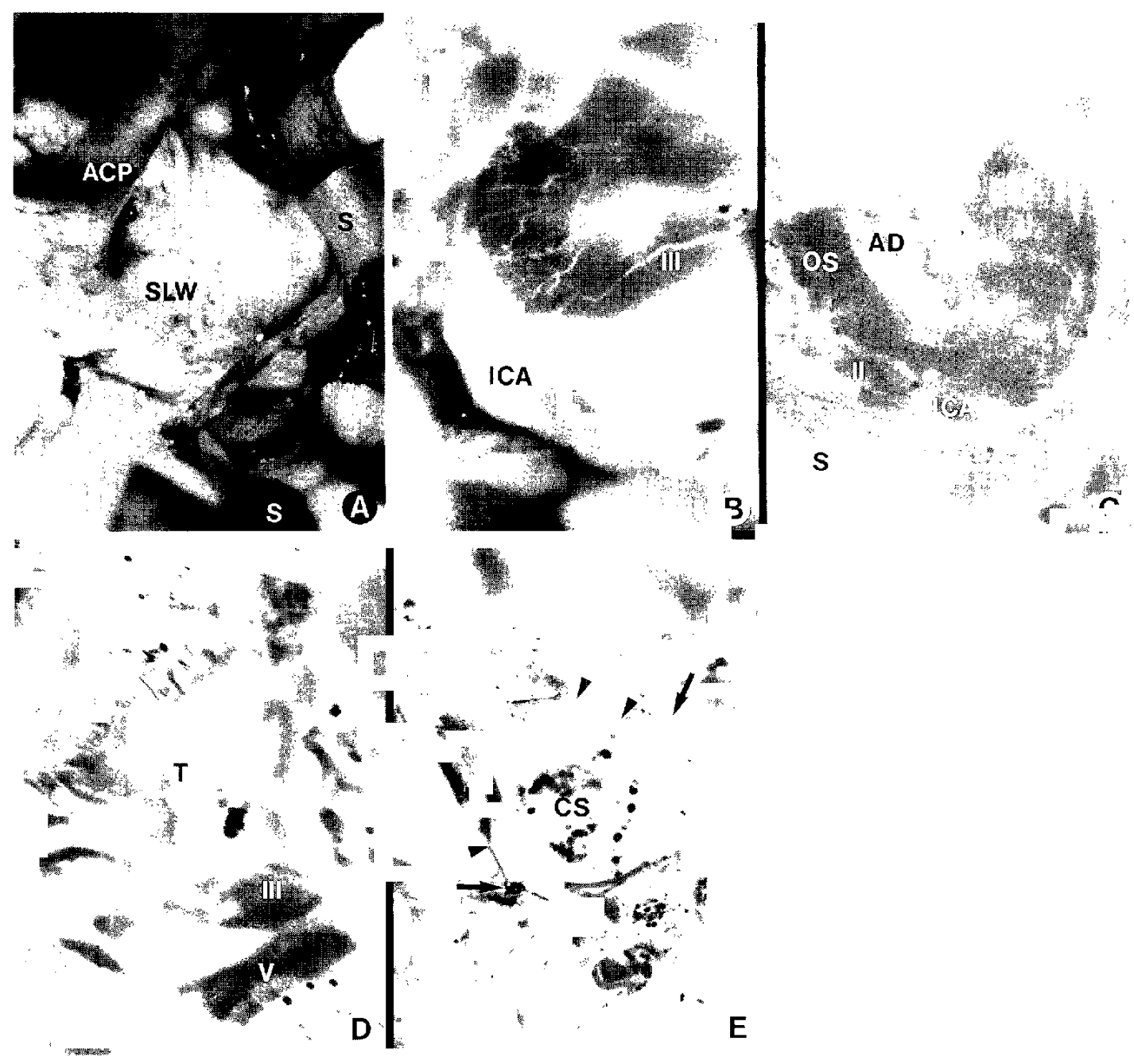

Fig. 2 Intraoperative photographs. A: Superolateral wall (SLW) of the right cavernous sinus markedly protrudes. ACP: anterior clinoid process, S: spatula, V: vein. B: At higher magnification, the oculomotor nerve (III) is completely involved in the tumor at the entrance to the cavernous sinus. ICA: internal carotid artery. C: Anterior clinoid process drilled away exposing the anterior triangle of Dolenc (AD). II: optic nerve, OS: optic sheath. D: The tumor (T) was totally removed along with the oculomotor nerve. E: After total tumor removal, the cavernous sinus (CS) was decompressed and blood circulation restored. Arrowheads indicate the opened thick dural membrane of the cavernous sinus. Arrows indicate the sutures between the thick dural membrane and the thin fibrous membrane. 

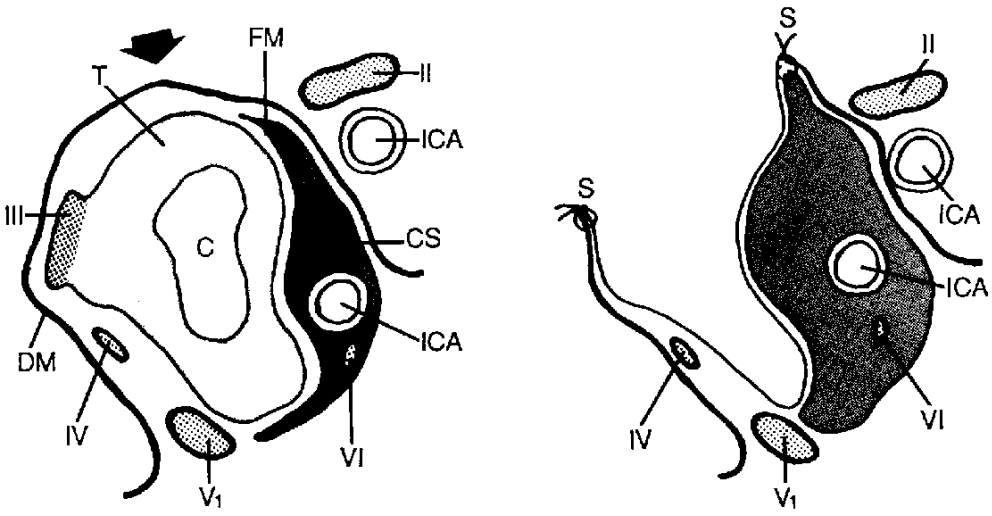

Fig. 3 Relationship between the tumor and surrounding structures confirmed intraoperatively. The tumor (T) was totally removed together with the oculomotor nerve (III) and sutures (S) placed in the thick dural membrane (DM) and the thin fibrous membrane (FM) of the cavernous venous cavity (CS). Cavernous sinus demonstrated restored blood circulation after tumor removal. Arrow indicates the operative direction. $\mathrm{C}$ : intratumoral cyst, ICA: internal carotid artery, II: optic nerve, IV: trochlear nerve, $\mathrm{V}_{1}$ : first branch of the trigeminal nerve, $\mathrm{VI}$ : abducens nerve.

lateral wall of the cavernous sinus (Fig. 2D). Normal oculomotor nerve was also clearly recognized at the entrance to the orbit distally and in the interpeduncular cistern proximally. The oculomotor nerve was resected between these two points, and the tumor completely removed, restoring the blood flow in the venous sinus. The thin fibrous membrane was recognized as a true wall between the venous cavity and the lateral wall of the cavernous sinus (Fig. 2E).

The postoperative course was uneventful. His only neurological deficit was a right oculomotor nerve paralysis. The abduction of the right eyeball was not aggravated postoperatively, and a complete recovery took place 5 days later. He remained unchanged 5 months after operation without any evidence of tumor recurrence.

\section{Discussion}

High-field MR imaging now provides useful information for surgeons such as the precise relationship between tumor, vessels, and nerves. Microsurgical anatomical investigations of the cavernous sinus indicate that the oculomotor and abducens nerves and the first branch of the trigeminal nerve run through the lateral wall of the cavernous sinus, ${ }^{2)}$ separated from the cavernous venous sinus by a thin membrane. ${ }^{7}$ Tumors originating from these nerves can theoretically be removed without bleeding from the cavernous sinus. In our case, the opened cavernous sinus was closed by suturing the external dural wall with the internal thin membrane. This procedure al- lowed tumor removal without entering the venous cavity. The relationship between the tumor and surrounding structure is shown in Fig. 3.

Only four cases of oculomotor neurinoma confirmed intraoperatively have been reported. ${ }^{3-6)}$ In three of the four, a small tumor was observed in the cisternal portion of the oculomotor nerve. ${ }^{3-5)}$ These tumors were easily removed together with the oculomotor nerve. The other case had a $25-\mathrm{mm}$ diameter tumor mainly situated in the lateral wall of the cavernous sinus, as in our case, but part of the tumor embedded in the cavernous sinus was not removed. ${ }^{6}$

Our understanding of the precise structure of the cavernous sinus helped to achieve hemostasis during removal of the tumor in the lateral wall of the cavernous sinus. This procedure caused little or no aggravation of the neurological signs frequently seen in previous cases.

\section{References}

1) Dolenc VV: Anatomy and Surgery of the Cavernous Sinus. Wien, Springer-Verlag, 1989, pp 3-87

2) Inoue $T$, Rhoton $A L J r$, Theele $D$, Barry ME: Surgical approaches to the cavernous sinus; A microsurgical study. Neurosurgery 26: 903-932, 1990

3) Kansu T, Özcan OE, Özdirim E, Önol B, Gürcay Ö: Neurinoma of the oculomotor nerve. Case report. $J$ Clin Neuro Ophthalmol 2: 271-272, 1982

4) Katsumata $Y$, Maehara $T$, Noda M, Shirouzu I: Neurinoma of the oculomotor nerve: $\mathrm{CT}$ and MR features. J Comput Assist Tomogr 14: 658-661, 1990

5) Nogami K, Nishijima $M$, Endo $S$, Takaku A: Neurinoma of the oculomotor nerve: Case report. No 
Shinkei Geka 14: 1237-1241, 1986 (in Japanese)

6) Takano S, Endo M, Miyasaki Y, Yada K, Ohwada T, Takagi H: Neurinoma of the oculomotor nerve. Case report. Neurol Med Chir (Tokyo) 30: 132-136, 1990

7) Umansky F, Nathan $H$ : The cavernous sinus. An anatomical study of its lateral wall, in Dolenc VV (ed): The Cavernous Sinus. A Multidisciplinary Approach to Vascular and Tumorous Lesion. Wien,
Springer-Verlag, 1987, pp 56-66

Address reprint requests to: Y. Kurokawa, M.D., Department of Neurosurgery, Kushiro City General Hospital, 1-12 Shunko-dai, Kushiro, Hokkaido 085, Japan. 